\title{
Association of Sequential Organ Failure Assessment (SOFA) components with mortality
}

Anssi Pölkki ( $\square$ anssi.polkki@kuh.fi )

Kuopio University Hospital: Kuopion yliopistollinen sairaala https://orcid.org/0000-0001-8777-5287

\section{Pirkka T Pekkarinen}

Division of Intensive Care Medicine, Department of Anaesthesiology, Intensie Care and Pain Medicine, University of Helsinki and Helsinki University Hospital

\section{Jukka Takala}

Inselspital University Hospital Bern: Inselspital Universitatsspital Bern

\section{Tuomas Selander}

Kuopio University Hospital: Kuopion yliopistollinen sairaala

\section{Matti Reinikainen}

Department of Anaesthesiology and Intensive Care, Kuopio University Hopsital and University of Eastern Finland

\section{Research}

Keywords: Sequential Organ Failure Assessment, SOFA score, SOFA score components, Intensive Care scoring systems, Mortality surrogates, Mortality prediction

Posted Date: June 2nd, 2021

DOI: https://doi.org/10.21203/rs.3.rs-556787/v1

License: (c) (1) This work is licensed under a Creative Commons Attribution 4.0 International License. Read Full License

Version of Record: A version of this preprint was published at Acta Anaesthesiologica Scandinavica on March 30th, 2022. See the published version at https://doi.org/10.1111/aas.14067. 


\section{Abstract}

\section{Background}

Sequential Organ Failure Assessment (SOFA) is a practical and widely used method to describe and quantify the presence and severity of organ system dysfunctions and failures. Some proposals suggest that SOFA could be employed as an endpoint in interventional trials. To justify this, all SOFA components should have comparable weights as organ dysfunction measures. In this study we aimed to investigate whether the associations of different SOFA components with in-hospital mortality are comparable.

\section{Methods}

We performed a study based on nationwide register data on adult patients admitted to 26 Finnish intensive care units (ICUs) during 2012-2015. We determined the SOFA score as the maximum score in the first 24 hours after ICU admission. We defined organ failure as an organ-specific SOFA score of three or higher. We evaluated the association of different SOFA component scores with mortality using multivariable logistic regression analysis.

\section{Results}

Our study population comprised 63,756 ICU patients. Overall hospital mortality was $10.7 \%$. In-hospital mortality was $22.5 \%$ for patients with respiratory failure, $34.8 \%$ for those with coagulation failure, $40.1 \%$ for those with hepatic failure, $14.9 \%$ for those with cardiovascular failure, $26.9 \%$ for those with neurologic failure and $34.6 \%$ for the patients with renal failure. The age-adjusted odds ratio for in-hospital death was 2.41 [95\% confidence interval $(\mathrm{Cl}) 2.27-2.56$ ] for respiratory failure, $4.04(95 \% \mathrm{Cl} 3.57-4.57)$ for coagulation failure, 4.24 (95\% Cl 3.47-5.17), for hepatic failure, 1.57 (95\% Cl 1.47-1.67) for cardiovascular failure, 5.00 (95\% Cl 4.71-5.30) for neurologic failure, and 4.93 (95\% Cl 4.58-5.32) for renal failure. Organ failure combinations including cardiovascular failure were associated with lower mortality than other organ failure combinations.

\section{Conclusions}

All SOFA components are associated with mortality, but their weights are not comparable. High cardiovascular SOFA scores do not imply an equally high risk as high scores of other components.

\section{Background}

The Sequential Organ Failure Assessment (SOFA), at first named Sepsis-related Organ Failure Assessment, was introduced by The Working Group on Sepsis-Related Problems in 1996 [1]. The SOFA score describes and quantifies the severity of dysfunction or failure of six essential organ systems (Appendix). Primarily, the SOFA score was not meant for outcome prediction. Multiple studies have shown, however, that it can rather well predict mortality in groups of critically ill patients [1-13]. This has notably widened the employment of the SOFA score beyond its original purpose. 
In randomised controlled trials (RCTs), the gold standard has been to use all-cause mortality as an endpoint. However, interventional trials often fail to detect any difference between study arms in mortality [14]. Therefore, there is growing interest to use surrogate endpoints, for example SOFA scores [15-17]. Regulatory authorities, including the European Medicines Agency (EMA), can under certain limitations approve the use of surrogate endpoints instead of mortality as primary endpoints [18].

The change in the SOFA score during critical illness has been proposed to reflect the benefit or harm of the intervention of interest. The SOFA score, which is a scalar variable, is presumably more sensitive in detecting the effects of an intervention than mortality, a binary variable. However, the total SOFA score cannot be an unbiased trial endpoint unless all its components have comparable weights as measures of organ dysfunction severity. Moreover, some organ failures are more likely to occur concurrently [3]. It is unclear whether different combinations of organ failures affect the predictive value of total SOFA score.

\section{Objectives}

The aim of this study was to investigate whether different SOFA score components, recorded during the first 24 hours of intensive care, are comparable in terms of their association with mortality. Mortality at hospital discharge was the primary endpoint. Mortality at ICU discharge and mortality within 12 months were secondary endpoints. We evaluated how combinations of different organ system failures are associated with mortality. Furthermore, we assessed the association of increasing SOFA scores with mortality across different admission groups.

\section{Methods}

\section{Study design and participants}

We performed a retrospective cohort study of data collected prospectively in the Finnish ICU quality register, the Finnish Intensive Care Consortium (FICC) database. The FICC is a national programme for benchmarking intensive care in Finland [19]. We included all adult patients admitted to 26 Finnish ICUs between January $1^{\text {st }}, 2012$ and December $31^{\text {st }}, 2015$. For patients with multiple ICU treatment periods during the same hospitalisation, we included only the first ICU admission. In line with the 1998 paper by the working group that created the SOFA system [2], we defined organ failure (OF) as an organ-specific SOFA score of three or higher. OF could appear isolated or as part of multiorgan failure.

We performed subgroup analyses to observe whether the findings were consistent, regardless of the admission type - medical, elective surgery and emergency surgery.

The study protocol was approved by the Research Ethics Committee of the Northern Savo Hospital District Data (225/13.02.00/2016), and research authorisation was obtained from the National Institute for Health and Welfare (THL/1585/5.05.00/2015).

\section{Extracted variables}


We extracted following variables from the FICC database: the most severe values of SOFA score components within the first 24 hours after admission to the ICU and the outcome variables: vital status at ICU discharge, at hospital discharge and 12 months after ICU admission. Moreover, we gathered baseline data on Acute Physiology, Age, Chronic Health Evaluation (APACHE) II [20], The Simplified Acute Physiology Score (SAPS) II [21], age, and sex. We also retrieved data on length of stay in the ICU and length of stay in hospital.

\section{Statistical methods and data handling}

We compared the characteristics of survivors and non-survivors at hospital discharge employing the Mann-Whitney U-test for continuous data and chi square test for categorical data. Using age-adjusted multivariable logistic regression, we evaluated the association between SOFA score components and mortality. We calculated Standardized Occurrence Ratio (SOR) for each set of at least two, three, or four concurrently occurring failing organ systems with $95 \%$ confidence interval. Bonferroni correction was used for multiple comparisons. SOR is a tool to evaluate whether particular organ failures occur concurrently more frequently than anticipated by merely observing the frequencies of organ failures. SOR was calculated as ], where is the number of patients with the particular organ failure combination observed, is the total number of admissions and and are the proportions of patients with failure of organ systems and , respectively. In the same way, we calculated the SOR for patients with three and four concurrent organ failures. SOR $>1$ signals that the odds of concurrent occurrence of these particular failing organ systems are increased.

We used IBM SPSS Statistics, Version 22 (IBM Corp., Amonk, NY, USA) and R statistical software version 4.04 for the statistical analyses.

In the neurologic component, the SOFA score is based on the Glasgow Coma Score (GCS). For anaesthetised or sedated patients, the GCS recorded to the FICC registry is the last reliable GCS preceding sedation, in line with the SAPS II score [21].

The hepatic SOFA score is based on the plasma bilirubin concentration. Bilirubin is normally measured when there is a clinical reason to suspect hepatic problems. Therefore, we consider normality of bilirubin concentrations as likely in patients for whom the data on bilirubin were missing. In these patients, we assumed the hepatic SOFA score to be zero. We made no assumption of normality for other SOFA components in cases of missing data. Therefore, we excluded patients with missing SOFA data concerning all other components except for the hepatic component. In addition, we excluded patients with missing mortality data.

\section{Results}

\section{Study population}


There were totally 71,492 ICU admissions during the study period. We excluded 4,289 (6\%) readmissions. Data were missing most commonly for the hepatic component, for 26,435 (39.3\%) admissions. For other components, data were missing for few admissions: 14 (0\%) in respiratory, 2,144 (3.2\%) in coagulation, $14(0 \%)$ in cardiovascular, $1,318(2 \%)$ in neurologic and $14(0 \%)$ in the renal component. We excluded 104 $(0.2 \%)$ cases with missing data on vital status at hospital discharge. The final study population included 63,756 patients (Additional file 1: Figure S1). For ICU and 12-month mortality calculations, we excluded $16(0 \%)$ cases with missing data on vital status at ICU discharge and $3,717(5.5 \%)$ cases with missing data on vital status at 12 months, respectively. The median age of the patients was 64 years (interquartile range 52-73), and the majority (63.7\%) were male. Baseline data are presented in Table 1. The distribution of SOFA component scores as well as the frequency of organ failures are presented in Fig. 1.

\section{ICU, hospital and 12-month mortality}

Overall, 6,851 (10.7\%) patients died in hospital. The first day total SOFA score was strongly associated with mortality (Fig. 2). Mortality was $5.3 \%$ at ICU discharge and $21.6 \%$ in 12 months. Mortality increased with increasing SOFA scores (Fig. 2).

Mortality mostly increased consistently with increasing SOFA component points (Fig. 3). The cardiovascular component, however, was an exception. In this component, a clear increase in mortality occurred only in the group with the score 4 . For the respiratory and coagulation components, mortality was similar for the scores of 0 and 1 points but increased consistently with increasing points thereafter. This pattern appeared rather similar regardless of whether the vital status was observed at ICU or hospital discharge or 12 months after ICU admission.

Respiratory failure was observed for 16277 (22.8\%) patients, coagulation failure for 1932 (2.7\%), hepatic failure for 704 (1.0\%), cardiovascular failure for 37672 (52.7\%), neurologic failure for 12714 (17.8\%), and renal failure for 5958 (8.3\%) patients (Fig. 1). Hospital mortality was $22.5 \%$ for patients with respiratory failure, $34.8 \%$ for those with coagulation failure, $40.1 \%$ for those with hepatic failure, $14.9 \%$ for those with cardiovascular failure, $26.9 \%$ for those with neurologic failure and $34.6 \%$ for the patients with renal failure.

The results of age-adjusted multivariable logistic regression analysis, with all components included simultaneously in the analysis, are presented in Table 2. The odds of in-hospital death were highest for patients with neurologic failure, whereas the odds of death were lowest in patients with cardiovascular failure. Especially for 12-month outcome, cardiovascular OF had little influence on the risk of death.

\section{Combinations of organ system failures and mortality}

Mortality increased with increasing numbers of concurrent organ failures (Fig. 4). Of all patients, $47.4 \%$ had at least two, $12.7 \%$ had at least three and $2.0 \%$ had at least four concurrent OFs. In-hospital mortalities in these groups were $35.8 \%, 54.1 \%$, and $71.8 \%$, respectively. SOR was $>1$ in $48(94.1 \%)$ out of all 51 OF combinations (Additional file 1: Table S1), suggesting that OFs are likely to occur concurrently. 
In-hospital mortality ranged between $25.7-65.2 \%$ in patients with two, $41.4-82.4 \%$ in those with three, and $52.9-85.7 \%$ in those with four failing organ systems, depending on which organ systems were failing. The variation in mortality according to the different sets of organ failures decreased towards 12-month mortality observation.

\section{Discussion}

In this large nationwide registry study on adult patients admitted to Finnish ICUs, we evaluated the patients' SOFA scores during the first $24 \mathrm{~h}$ in the ICU and assessed the prevalence of different organ failures, defined as the organ system-specific SOFA score of 3 or 4, and their associations with mortality. Cardiovascular failure, observed in $53 \%$ of patients, was the most common, followed by respiratory failure $(23 \%)$, neurologic (18\%), renal failure $(8 \%)$, coagulation failure $(3 \%)$ and hepatic failure $(1 \%)$. Mortality increased with increasing SOFA scores. However, scores reflecting dysfunctions of different organ systems were not equivalent as metrics of risk. In particular, high cardiovascular SOFA scores did not imply as high a risk of death as high scores of other SOFA components. In addition, OF combinations including cardiovascular failure were associated with lower mortality than other OF combinations: hospital mortality was in the range $25-45 \%$ for patients with cardiovascular failure together with another organ failure, whereas mortality exceeded $50 \%$ for all other organ failure combinations except the combination of neurologic and respiratory failure (40\%).

Our findings contradict those of the 1999 study by the Working Group on Sepsis Related Problems, where cardiovascular SOFA scores contributed more strongly than scores of other components to poor outcomes [3]. However, our results are in accordance with the study by Gupta et al. on 2,796 septic patients with in-hospital mortality of $10 \%$. Coagulation dysfunction or failure predicted a higher and cardiovascular dysfunction or failure a lower risk increase compared to dysfunctions of other organ systems [22].

Although high SOFA scores often indicate a poor prognosis, cardiovascular scores seem to be an exception. This may reflect a change in clinical practices in recent years. The SOFA score was introduced in an era of more restricted use of vasopressors. During the last two decades, the use of norepinephrine has become more common [23-25]. Vasopressor treatment is initiated earlier without preceding large doses of resuscitation fluids [26-29]. An infusion of norepinephrine lasting at least one hour, even at a small dose, assigns three points to the cardiovascular component of the SOFA score. Moreover, an infusion rate exceeding $0.1 \mu \mathrm{g} / \mathrm{kg} / \mathrm{min}$, which is not a particularly high dose in contemporary intensive care, gives four points. Because of this change in clinical practice, the cardiovascular SOFA score seems to have suffered from inflation. In addition, variations in blood pressure targets and concomitant treatments, particularly sedation, are likely to contribute to the amount of norepinephrine administered and thus to cardiovascular SOFA scores.

The distribution of the cardiovascular SOFA score had two peaks, made up of categories $0-1$ and 3-4. A score of 2 was uncommon, present for roughly $1 \%$ of the patients. Two cardiovascular SOFA points are 
scored to patients who are administered dopamine at a dose less than $5 \mu \mathrm{g} / \mathrm{kg} /$ minute or dobutamine at any dose. A number of recent guidelines recommend against or advise specific caution for monotherapy use of these inotropes in circulatory shock [30,31]. However, administering dopamine to brain-dead organ donors with the intention to support renal function was relatively common in Finland during the study period [32], which may partly explain the high mortality in this SOFA category.

The impact of the SOFA component scores on mortality seems to be somewhat dependent on the length of follow-up. Hepatic failure was associated with increased ICU mortality but even more remarkably with 12-month mortality. A plausible explanation for this finding is that severe hepatic failure is often an acuteon-chronic type of disease associated with poor long-term prognosis [33]. In the 1999 study by Moreno et al., increased hepatic SOFA scores were the only ones without any association with outcome [3]. However, the endpoint was vital status at ICU discharge. Hepatic failure seems to become more important when the follow-up is longer.

In our study, increased neurologic SOFA scores were associated with both short-term and long-term mortality with no marked change in odds ratios for death over time. In turn, failures of the respiratory, coagulation, cardiovascular and renal organ systems were more strongly associated with short-term mortality than 12-month mortality. This phenomenon was most prominent for cardiovascular OF, which only slightly increased the risk of death within 12 months. Previous studies observing the predictive value of SOFA score have mainly focused on short-term mortality. Pekkarinen et al. observed the association of the first 24 hours extracerebral SOFA scores in cardiac arrest patients with 12-month survival. In line with our findings, they found the cardiovascular SOFA scores as the only ones without association with unfavourable long-term outcome [34]. To the best of our knowledge, however, our study is the first one assessing the predictive value of SOFA score components with a 12-month follow-up in unselected population.

Risk of death increases with an increasing amount of failing organ systems [35,36]. Our findings imply that some OFs are more likely to occur concurrently than other failures. Moreover, mortality was dependent on which organ systems were failing. The Working group on sepsis-related problems demonstrated a pattern for concurrently occurring organ failures by means of principal components analysis [3]. The group identified two common organ failure combinations. The first combination comprised respiratory, cardiovascular and neurologic OFs, whereas the second comprised coagulation, hepatic and renal OFs. In our study, this first combination of respiratory, cardiovascular and neurologic OFs was also the most common of the combinations with three OFs, affecting $37 \%$ of patients with at least three concurrently failing organ systems. However, these three organ systems were most commonly failing systems in general.

Remarkably, we found that the second combination, which comprised coagulation, hepatic and renal OFs, occurred 44 times more often than one would have expected by observing merely the frequency of these organ failures in the whole study population. It is also noteworthy that the most common OF combination with respiratory, cardiovascular and neurologic failures was associated with more favourable outcomes 
than other combinations of three concurrent OFs. The in-hospital and 12-month mortalities associated with this particular combination were $41 \%$ and $55 \%$, respectively, whereas in-hospital and 12-month mortalities of patients with other triple OF combinations ranged between $56-82 \%$ and $63-88 \%$, respectively.

Outcomes of ICU patients have improved over the years. In 1998, Vincent et al. reported an ICU mortality of $90 \%$ in patients with a SOFA score above 15 [2], whereas in-hospital mortality for patients with first-day SOFA score above 15 was $72 \%$ in our study (Fig. 2).

There is growing interest in employing the SOFA score as a surrogate endpoint for mortality in clinical trials [17]. Our findings suggest that this may not be without problems. Regarding risk of death, weights of different SOFA component scores are different, and the prognosis of patients with multi-organ failure is dependent on which organ systems fail. In addition, different organ failures may have different impacts on long-term mortality despite comparable effects on short-term mortality.

Our study population consisted of a large unselected group of patients treated in Finnish ICUs in 20122015. All general ICUs in Finland were included. Therefore, our study population is well representative of Finnish adult ICU patients. We do not know whether the results are generalizable to health care systems in other countries. However, early use of norepinephrine has become more common in other countries as well [25], and it is likely that the relation between cardiovascular SOFA scores and mortality may have weakened also in other countries.

\section{Strengths and limitations of the study}

Our study has several strengths. We performed a nationwide multicentre study with a final cohort of 63,756 patients aged 18 years or older. The data were retrieved from a high-quality national database with all Finnish general ICUs participating.

A major limitation of our study is that the SOFA scores are based only on measurements during the first 24 hours after admission to the ICU, whereas previous studies have shown that a change in SOFA score over time is the most reliable predictor of mortality $[37,38]$.

\section{Conclusion}

All SOFA components are associated with mortality. However, high cardiovascular SOFA scores did not bring as high a risk of death as high scores of other SOFA components. Moreover, OF combinations including cardiovascular failure were associated with lower mortality than other organ failure combinations. OFs are likely to occur concurrently.

\section{Abbreviations}


AIDS: Acquired Immune Deficiency Syndrome

APACHE: Acute Physiology, Age, Chronic Health Evaluation

Cl: Confidence Interval

ICU: Intensive Care Unit

IQR: Inter-quartile Range

MAP: Mean arterial pressure

NYHA: New York Heart Association

LOS: Length of stay

OF: Organ Failure

OR: Odds Ratio

PaO2: Partial arterial pressure of oxygen

$\mathrm{PaO2} / \mathrm{FiO2}$ : Ratio of arterial partial pressure of oxygen divided by fraction of inspired oxygen

SAPS: Simplified Acute Physiology Score

SD: Standard Deviation

SOFA: Sequential Organ Failure Assessment

SOR: Standardized Occurrence Ratio

\section{Declarations}

\section{Ethics and declarations}

Ethics approval and consent to participate

The study's protocol was approved by the Research Ethics Committee of the Northern Savo Hospital District Data (225/13.02.00/2016).

\section{Consent for publication}

Not applicable

\section{Competing interests}


The authors declare that they have no competing interests.

\section{Availability of data and materials}

The data were used with permission given by the National Institute for Health and Welfare to the study group. The data are not publicly available.

\section{Funding}

Dr Pölkki was supported by institutional funding from Kuopio University Hospital and University of Eastern Finland.

Otherwise the authors declare that they received no specific funding for this study.

\section{Authors'contributions}

MR presented the first idea of the study. AP analysed and interpreted the data, supported by MR and PP. AP drafted the first version of the manuscript and created the figures. TS contributed in statistical analysis. JT is one of the original creators of the SOFA score and he helped in interpreting the results. All authors revised the manuscript and read and approved the final manuscript.

\section{Acknowledgements}

We are grateful to the doctors and nurses in the ICUs participating in the Finnish Intensive Care Consortium for careful data documentation and to TietoEVRY for managing the database.

\section{Authors' information}

\section{Anssi Pölkki}

University of Eastern Finland, Kuopio, Finland

Department of Anaesthesiology and Intensive Care, Kuopio University Hospital, Kuopio, Finland

\section{Pirkka T. Pekkarinen}

Division of Intensive Care Medicine, Department of Anaesthesiology, Intensive Care and Pain Medicine, University of Helsinki and Helsinki University Hospital, Helsinki, Finland

\section{Jukka Takala}

Department of Intensive Care Medicine, University Hospital Bern (Inselspital), University of Bern, Bern, Switzerland

Tuomas Selander 
Science Service Center, Kuopio University Hospital, Kuopio, Finland

\section{Matti Reinikainen}

University of Eastern Finland, Kuopio, Finland

Department of Anaesthesiology and Intensive Care, Kuopio University Hospital, Kuopio, Finland

\section{Appendix}

Table 1. The Sequential Organ Failure Assessment (SOFA) The score was introduced by Vincent et al. [1] in 1996.

\begin{tabular}{|c|c|c|c|c|}
\hline SOFA score & 1 & 2 & 3 & 4 \\
\hline \multicolumn{5}{|l|}{ Respiration } \\
\hline $\begin{array}{l}\mathrm{PaO}_{2} / \mathrm{FiO}_{2} \\
\mathrm{mmHg}\end{array}$ & $<400$ & $<300$ & $<200 *$ & $<100 *$ \\
\hline \multicolumn{5}{|l|}{ Coagulation } \\
\hline $\begin{array}{l}\text { Platelets } \\
\times 10^{3} / \mathrm{mm}^{3}\end{array}$ & $<150$ & $<100$ & $<50$ & $<20$ \\
\hline \multicolumn{5}{|l|}{ Hepatic } \\
\hline Bilirubin, $\mathrm{mg} / \mathrm{dL}$ & $\begin{array}{l}1.2- \\
1.9\end{array}$ & $2.0-5.9$ & $6.0-11.9$ & $>12.0$ \\
\hline$(\mu \mathrm{mol} / \mathrm{l})$ & $\begin{array}{l}20- \\
32\end{array}$ & $33-101$ & $102-204$ & $>204$ \\
\hline \multicolumn{5}{|l|}{ Cardiovascular } \\
\hline Hypotension & $\begin{array}{l}\text { MAP } \\
<70\end{array}$ & $\begin{array}{l}\text { Dopamine } \leq 5 \\
\text { or dobutamine } \\
\text { (any) }\end{array}$ & $\begin{array}{l}\text { Dopamine }>5 \text { or } \\
\text { norepinephrine } \leq 0.1 \text { or } \\
\text { epinephrine } \leq 0.1 * \star\end{array}$ & $\begin{array}{l}\text { Dopamine }>15 \text { or } \\
\text { norepinephrine }>0.1 \text { or } \\
\text { epinephrine }>0.1 * *\end{array}$ \\
\hline \multicolumn{5}{|l|}{ Neurologic } \\
\hline $\begin{array}{l}\text { Glasgow Coma } \\
\text { Score }\end{array}$ & $\begin{array}{l}13- \\
14\end{array}$ & $10-12$ & $6-9$ & $<6$ \\
\hline \multicolumn{5}{|l|}{ Renal } \\
\hline $\begin{array}{l}\text { Creatinine, } \mathrm{mg} / \mathrm{dL} \\
\text { (mmol /I) or urine } \\
\text { output }\end{array}$ & $\begin{array}{l}1.2- \\
1.9 \\
(110- \\
170)\end{array}$ & $\begin{array}{l}2.0-3.4 \\
(171-299)\end{array}$ & $\begin{array}{l}3.5-4.9(300-440) \text { or } \\
<500 \mathrm{ml} / \mathrm{day}\end{array}$ & $\begin{array}{l}>5.0(>440) \text { or } \\
<200 \mathrm{ml} / \mathrm{day}\end{array}$ \\
\hline
\end{tabular}

*Patients treated with mechanical respiratory support 
${ }^{\star \star}$ Adrenergic agents administered for at least $1 \mathrm{hr}$ (doses given in $\mu \mathrm{g} / \mathrm{kg} / \mathrm{min}$ ).

Abbreviations: $\mathrm{PaO}_{2}$, Partial arterial oxygen saturation; MAP, Mean arterial pressure.

\section{References}

1. Vincent JL, Moreno R, Takala J, Willatts S, de Mendonça A, Bruining H, et al. The SOFA (Sepsisrelated Organ Failure Assessment) score to describe organ dysfunction/failure. Intensive Care Med. 1996;22:707-10.

2. Vincent JL, de Mendonça A, Cantraine F, Moreno R, Takala J, Suter P, et al. Use of the SOFA score to assess the incidence of organ dysfunction/failure in intensive care units. Crit Care Med. 1998;26:1793-800.

3. Moreno R, Vincent J, Matos R, Mendonça A, Cantraine F, Thijs L, et al. The use of maximum SOFA score to quantify organ dysfunction/failure in intensive care. Results of a prospective, multicentre study. Intensive Care Med. 1999;25:686-96.

4. Ferreira FL, Bota DP, Bross A, Melot C, Vincent JL. How changes in SOFA score can predict outcome. Crit Care Med. 1999;27:A50.

5. Jentzer JC, Bennett C, Wiley BM, Murphree DH, Keegan MT, et al. Predictive value of individual Sequential Organ Failure Assessment sub-scores for mortality in the cardiac intensive care unit. PLoS One. 2019;14:e0216177.

6. Karakike E, Kyriazopoulou, E, Tsangaris I, Routsi C, Vincent JL, Giamarellos-Bourboulis EJ. The early change of SOFA score as a prognostic marker of 28-day sepsis mortality: analysis through a derivation and a validation cohort. Crit Care. 2019;23:

7. Innocenti F, Tozzi C, Donnini C, De Villa E, Conti A, Zanobetti M, et al. SOFA score in septic patients: incremental prognostic value over age, comorbidities, and parameters of sepsis severity. Intern Emerg Med. 2019;13:405-12.

8. Kajdacsy-Balla Amaral AC, Andrade FM, Moreno R, Artigas A, Cantraine F, Vincent JL. Use of the Sequential Organ Failure Assessment score as a severity score. Intensive Care Med. 2005;31:243-9.

9. Peres Bota D, Melot C, Lopes Ferreira F, Nguyen BV, Vincent JL. The Multiple Organ Dysfunction Score (MODS) versus the Sequential Organ Failure Assessment (SOFA) score in outcome prediction. Intensive Care Med. 2002;28:1619-24.

10. Raith EP, Udy AA, Bailey M, McGloughlin S, Maclsaac C, Bellomo R, et al. Prognostic Accuracy of the SOFA Score, SIRS Criteria, and qSOFA Score for In-Hospital Mortality Among Adults With Suspected Infection Admitted to the Intensive Care Unit. 2017;317:290-300.

11. Jones AE, Trzeciak S, Kline JA. The Sequential Organ Failure Assessment score for predicting outcome in patients with severe sepsis and evidence of hypoperfusion at the time of emergency department presentation. Crit Care Med. 2009;37:1649-

12. Basile-Filho A, Lago AF, Menegueti MG, Nicolini EA, Nunes RS, Lima SL, et al. The use of SAPS 3, SOFA, and Glasgow Coma Scale to predict mortality in patients with subarachnoid hemorrhage. 
Medicine. 2018;97:e12769.

13. Sekulic A, Marinkovic O, Malenkovic V, Trpkovic S, Pavlovic A. Application of APACHE II, SAPS II, SOFA and MODS scores in predicting outcome of severe acute pancreatitis (SAP). Eur J Anaesthesiol. 2014;31:209.

14. Santacruz CA, Pereira AJ, Celis E, Vincent JL. Which Multicenter Randomized Controlled Trials in Critical Care Medicine Have Shown Reduced Mortality? A Systematic Review. Crit Care Med. 2019;47:1680-91.

15. Vincent JL. We should abandon randomized controlled trials in the intensive care unit. Crit. Care Med. 2010;38:S534-8.

16. Vincent JL. Endpoints in sepsis trials: more than just 28-day mortality? Crit Care Med. 2004;32:S20913.

17. Lambden S, Laterre PF, Levy MM, Francois B. The SOFA score-development, utility and challenges of accurate assessment in clinical trials. Crit Care. 2019;23:

18. Guideline on clinical investigation of medicinal products for the treatment of sepsis. Edited by European Medicine Agency. CHMP/EWP/4713/03 2006.

19. Reinikainen M, Mussalo P, Hovilehto S, Uusaro A, Varpula T, Kari A, et al. Finnish Intensive Care Consortium, Association of automated data collection and data completeness with outcomes of intensive care. A new customised model for outcome prediction. Acta Anaesthesiol Scand. 2012;56:1114-22.

20. Knaus WA, Draper EA, Wagner DP, Zimmerman JE. APACHE II: a severity of disease classification system. Crit. Care Med. 1985;13:818-29.

21. Le Gall JR, Lemeshow S, Saulnier. A new Simplified Acute Physiology Score (SAPS II) based on a European/North American multicenter study. JAMA. 1993;270:2957-63.

22. Gupta T, Puskarich MA, DeVos E, Javed A, Smotherman C, Sterling SA, et al. Sequential Organ Failure Assessment Component Score Prediction of In-hospital Mortality From Sepsis. J Intensive Care Med. 2020;35:810-7.

23. Jentzer JC, Wiley B, Bennett C, Murphree DH, Keegan MT, Kashani KB, et al. Temporal Trends and Clinical Outcomes Associated with Vasopressor and Inotrope Use in The Cardiac Intensive Care Unit. 2020;53:452-9.

24. Thongprayoon C, Cheungpasitporn W, Harrison AM, Carrera P, Srivali N, Kittamongkolchai W, et al. Temporal trends in the utilization of vasopressors in intensive care units: an epidemiologic study. BMC Pharmacol. Toxicol. 2016;17:19.

25. Scheeren TWL, Bakker J, De Backer D, Annane D, Asfar P, Boerma, EC, et al. Current use of vasopressors in septic shock. Ann Intensive Care. 2019;9:

26. Marik PE, Linde-Zwirble WT, Bittner EA, Sahatjian J, Hansell D. Fluid administration in severe sepsis and septic shock, patterns and outcomes: an analysis of a large national database. Intensive Care Med. 2017;43:625-32. 
27. Pittard MG, Huang SJ, McLean AS, Orde SR. Association of positive fluid balance and mortality in sepsis and septic shock in an Australian cohort. Intensive Care. 2017;45:737-43.

28. Boyd JH, Forbes J, Nakada T-A, Walley KR, Russell JA. Fluid resuscitation in septic shock: a positive fluid balance and elevated central venous pressure are associated with increased mortality. Crit Care Med. 2011;39:259-65.

29. Maheshwari K, Nathanson BH, Munson SH, Khangulov V, Stevens M, Badani H, et al. The relationship between ICU hypotension and in-hospital mortality and morbidity in septic patients. Intensive Care Med. 2018;44:857-67.

30. Møller MH, Granholm A, Junttila E, Haney M, Oscarsson-Tibblin A, Haavind A, et al. Scandinavian SSAI clinical practice guideline on choice of inotropic agent for patients with acute circulatory failure. Acta Anaesthesiol Scand. 2018;62:420-50.

31. Ponikowski P, Voors AA, Anker SD, Bueno H, Cleland JGF, Coats AJS, et al. ESC Scientific Document Group, 2016 ESC Guidelines for the diagnosis and treatment of acute and chronic heart failure: The Task Force for the diagnosis and treatment of acute and chronic heart failure of the European Society of Cardiology (ESC) Developed with the special contribution of the Heart Failure Association (HFA) of the ESC. Heart J. 2016;37:2129-200

32. Mundt HM, Yard BA, Krämer BK, Benck U, Schnülle P. Optimized donor management and organ preservation before kidney transplantation. Int. 2016;29:974-84

33. Horvatits T, Drolz A, Trauner M, Fuhrmann V. Liver Injury and Failure in Critical Illness. Hepatology 2019;70:2204-21.

34. Pekkarinen, P.T., Bäcklund, M., Efendijev, I. et al.Association of extracerebral organ failure with 1-year survival and healthcare-associated costs after cardiac arrest: an observational database study. Crit Care2019;23:67.

35. Knaus WA, Draper EA, Wagner DP, Zimmerman JE. Prognosis in acute organ-system failure. Ann Surg. 1985;202:685-93.

36. Hebert PC, Drummond AJ, Singer J, Bernard GR, Russell JA. A simple multiple system organ failure scoring system predicts mortality of patients who have sepsis syndrome. Chest. 1993;104:230-5

37. Levy MM, Macias WL, Vincent JL, Russell JA, Silva E, Trzaskoma B, et al. Early changes in organ function predict eventual survival in severe sepsis. Crit Care Med. 2005;33:2194-201

38. de Grooth H, Geenen IL, Girbes AR, Vincent JL, Parienti J-J, Oudemans-Van Straaten H. SOFA and mortality endpoints in randomized controlled trials: a systematic review and meta-regression analysis. Crit Care 2017;21:38.

\section{Tables}

Table 1. Demographics, baseline characteristics and lengths of stay in ICU and hospital. 


\begin{tabular}{|c|c|c|c|c|}
\hline & $\begin{array}{l}\text { Overall } \\
(n=63,756)\end{array}$ & $\begin{array}{l}\text { Survivors } \\
(n=56,905)\end{array}$ & $\begin{array}{l}\text { Non-survivors } \\
(n=6,851)\end{array}$ & p-value \\
\hline Age, median (IQR) & $64(52-73)$ & $63(51-73)$ & $69(61-77)$ & $<0.001$ \\
\hline Female, n (\%) & $23121(36.3 \%)$ & $20642(36.3 \%)$ & $2479(36.2 \%)$ & 0.87 \\
\hline SOFA & $6(4-8)$ & $6(3-8)$ & $10(7-12)$ & $<0.001$ \\
\hline SAPS II & $31(23-44)$ & $29(22-40)$ & $56(44-69)$ & $<0.001$ \\
\hline APACHE II & $18(13-24)$ & $17(12-22)$ & $29(24-35)$ & $<0.001$ \\
\hline Metastatic cancer & $1550(2.4 \%)$ & 1295 (2.3\%) & $255(3.7 \%)$ & $<0.001$ \\
\hline Haematologic malignancy & $886(1.4 \%)$ & $650(1.1 \%)$ & $236(3.6 \%)$ & $<0.001$ \\
\hline AIDS & $71(0.1 \%)$ & $60(0.1 \%)$ & $11(0.2 \%)$ & 0.02 \\
\hline Admission type & & & & $<0.001$ \\
\hline Medical & 34987 (55.2\%) & $29651(52.5 \%)$ & $5336(78.1 \%)$ & \\
\hline Elective surgery & $17034(26.8 \%)$ & $16774(29.6 \%)$ & $260(3.8 \%)$ & \\
\hline Emergency surgery & 11401 (17.9\%) & $10165(17.9 \%)$ & $1236(18.1 \%)$ & \\
\hline Diagnostic category & & & & $<0.001$ \\
\hline Cardiovascular surgery & $15130(23.7 \%)$ & $14619(25.7 \%)$ & $517(7.5 \%)$ & \\
\hline Neurologic & 10753 (16.9\%) & $9756(17.1 \%)$ & $997(14.6 \%)$ & \\
\hline Cardiovascular insufficiency & $8967(14.1 \%)$ & $6651(11.7 \%)$ & $2316(33.8 \%)$ & \\
\hline Metabolic or renal & $6862(10.8 \%)$ & $5961(10.5 \%)$ & $901(13.2 \%)$ & \\
\hline Respiratory insufficiency & $5989(9.4 \%)$ & $4987(8.8 \%)$ & $1002(14.6 \%)$ & \\
\hline Gastrointestinal surgery & $4886(7.7 \%)$ & $4288(7.5 \%)$ & $598(8.7 \%)$ & \\
\hline Trauma & $4316(6.8 \%)$ & $4043(7.1 \%)$ & $273(4.0 \%)$ & \\
\hline Other postoperative cause & $2769(4.3 \%)$ & $2664(4.7 \%)$ & $105(1.5 \%)$ & \\
\hline Intoxication & $2666(4.2 \%)$ & $2615(4.6 \%)$ & $51(0.7 \%)$ & \\
\hline Miscellaneous & $1397(2.2 \%)$ & $1307(2.3 \%)$ & $90(1.3 \%)$ & \\
\hline LOS ICU (days), median (IQR), & $1.4(0.9-3.1)$ & $1.3(0.9-2.9)$ & $2.1(0.9-5.1)$ & $<0.001$ \\
\hline LOS Hospital (days), median (IQR) & $8(5-14)$ & $8(5-14)$ & $5(2-13)$ & $<0.001$ \\
\hline
\end{tabular}

Data are presented as numbers with percentages or as medians (inter-quartile ranges). Characteristics of hospital survivors and non-survivors were compared with the Mann-Whitney U-test for continuous data 
and Chi squared test for categorical data.

Abbreviations: IQR, Inter-quartile range; SOFA, Sequential Organ Failure Assessment; SAPS, Simplified Acute Physiology Score; APACHE, Acute Physiology And Health Evaluation; AIDS, Acquired Immune Deficiency Syndrome; LOS, Length of stay; ICU, Intensive Care Unit; SD, Standard Deviation

Table 2. The association of failures of different organ systems and age with ICU, hospital and 12-month mortality.

\begin{tabular}{|llllllllll|}
\hline & \multicolumn{3}{l}{ ICU mortality } & \multicolumn{3}{c}{ Hospital mortality } & \multicolumn{3}{l|}{12 -month mortality } \\
\hline & OR & \multicolumn{2}{l}{$95 \% \mathrm{Cl}$} & \multicolumn{2}{l}{ OR } & $95 \% \mathrm{Cl}$ & \multicolumn{2}{l|}{ OR } & $95 \% \mathrm{Cl}$ \\
\hline Respiratory OF & 2.90 & 2.68 & 3.13 & 2.41 & 2.27 & 2.56 & 1.71 & 1.63 & 1.80 \\
\hline Coagulation OF & 4.20 & 3.64 & 4.83 & 4.04 & 3.57 & 4.57 & 3.23 & 2.88 & 3.62 \\
\hline Hepatic OF & 2.26 & 1.77 & 2.88 & 4.24 & 3.47 & 5.17 & 4.24 & 3.51 & 5.13 \\
\hline Cardiovascular OF & 2.13 & 1.94 & 2.34 & 1.57 & 1.47 & 1.67 & 1.06 & 1.01 & 1.10 \\
\hline Neurologic OF & 4.64 & 4.29 & 5.02 & 5.00 & 4.71 & 5.30 & 4.12 & 3.92 & 4.33 \\
\hline Renal OF & 5.97 & 5.46 & 6.53 & 4.93 & 4.58 & 5.32 & 3.81 & 3.56 & 4.08 \\
\hline Age (for each year) & 1.01 & 1.01 & 1.02 & 1.03 & 1.03 & 1.04 & 1.04 & 1.04 & 1.04 \\
\hline
\end{tabular}

OF, Organ Failure; OR, odds ratio; $\mathrm{Cl}$, confidence interval

\section{Figures}



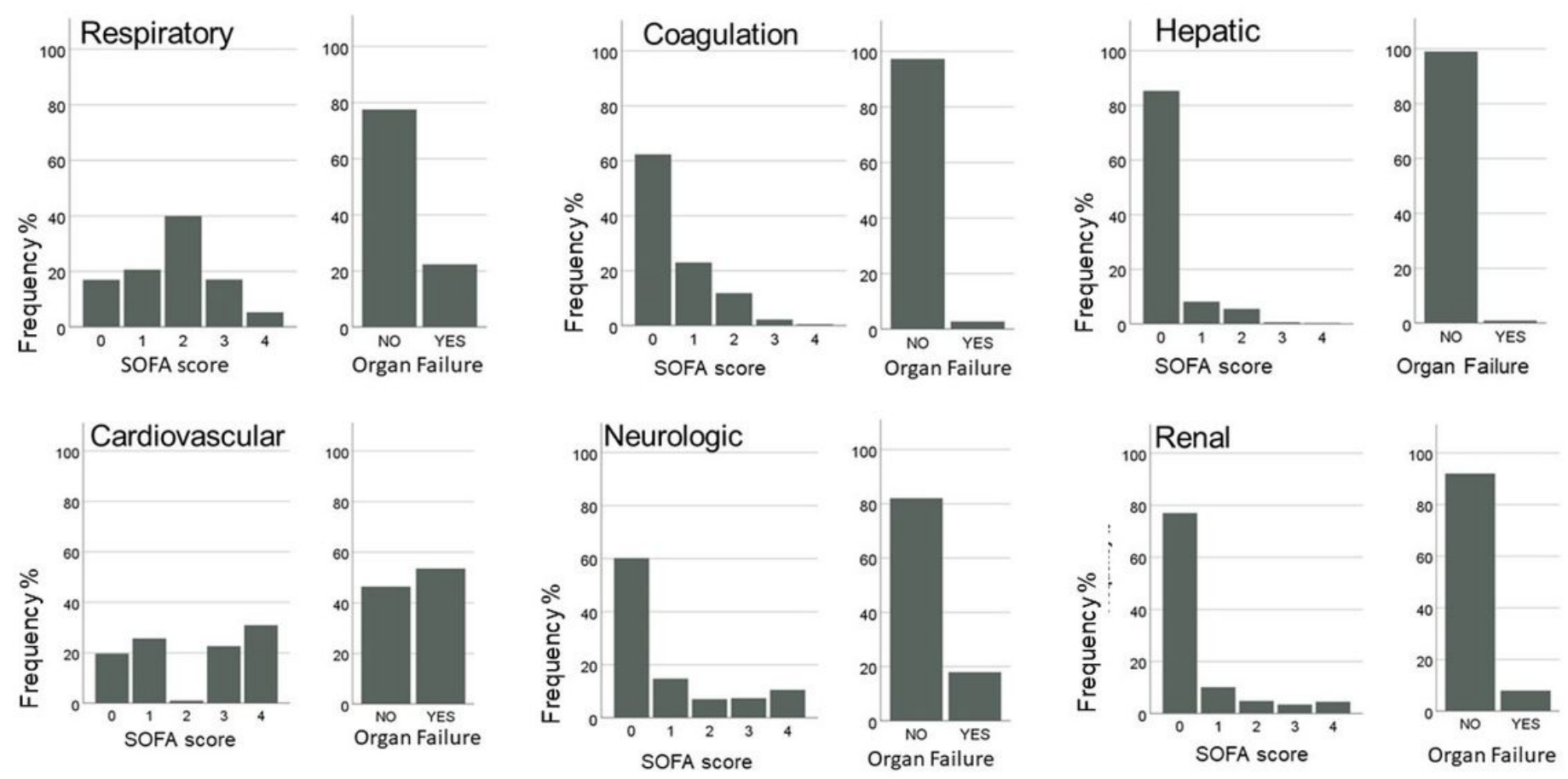

\section{Figure 1}

The distribution of SOFA component scores and frequency of organ failures The median score in the respiratory component was 2 . The median score in the cardiovascular component was 3 . In the cardiovascular component, the scores were almost equally distributed among the patients except for score 2, which was documented for only $678(1.1 \%)$ patients. In all other components (coagulation, hepatic, neurological and renal), the median score was 0 , with the score 1 being second most common. Of organ failures (OF), defined as an organ-specific SOFA score $\geq 3$, the most common OF was cardiovascular failure, in $53.6 \%$ of patients. The second most common OF was respiratory failure, in $22.5 \%$ of patients. 


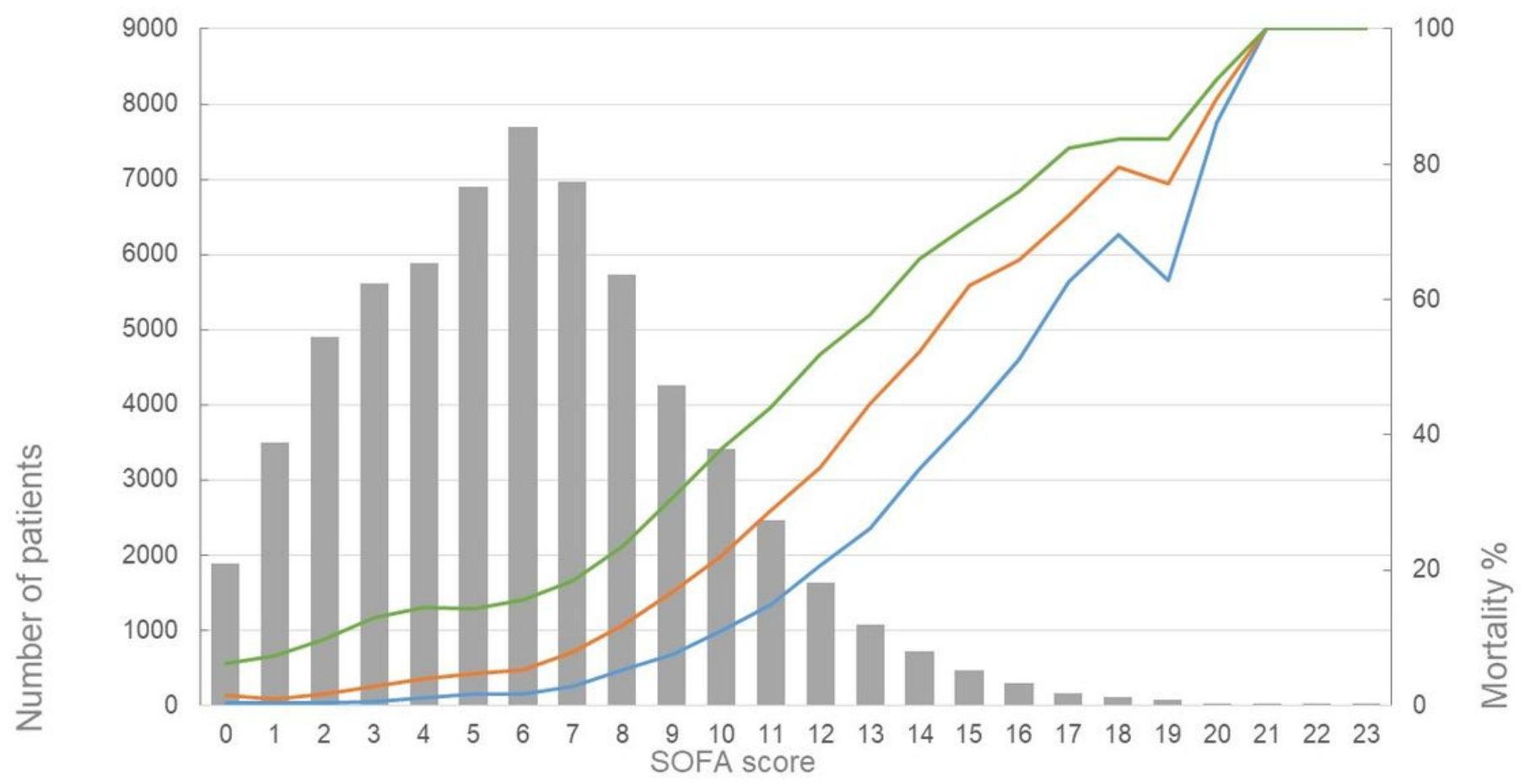

Figure 2

The number of patients and mortality according to first-day total SOFA score. ICU mortality (blue line), inhospital mortality (red line) and 12-month mortality (green line) increased with increasing total SOFA score. The bars present the number of patients within each total SOFA score group. The median SOFA score was 6 (inter-quartile range 4-8). The ICU mortality, in-hospital mortality and 12-month mortality increased linearly with increasing SOFA scores in patients with 6 or more SOFA scores. There were 642 (1\%) patients with a SOFA score over 15 . In these patients, ICU mortality was $60 \%$, hospital mortality was $72 \%$ and 12 -month mortality was $80 \%$. 

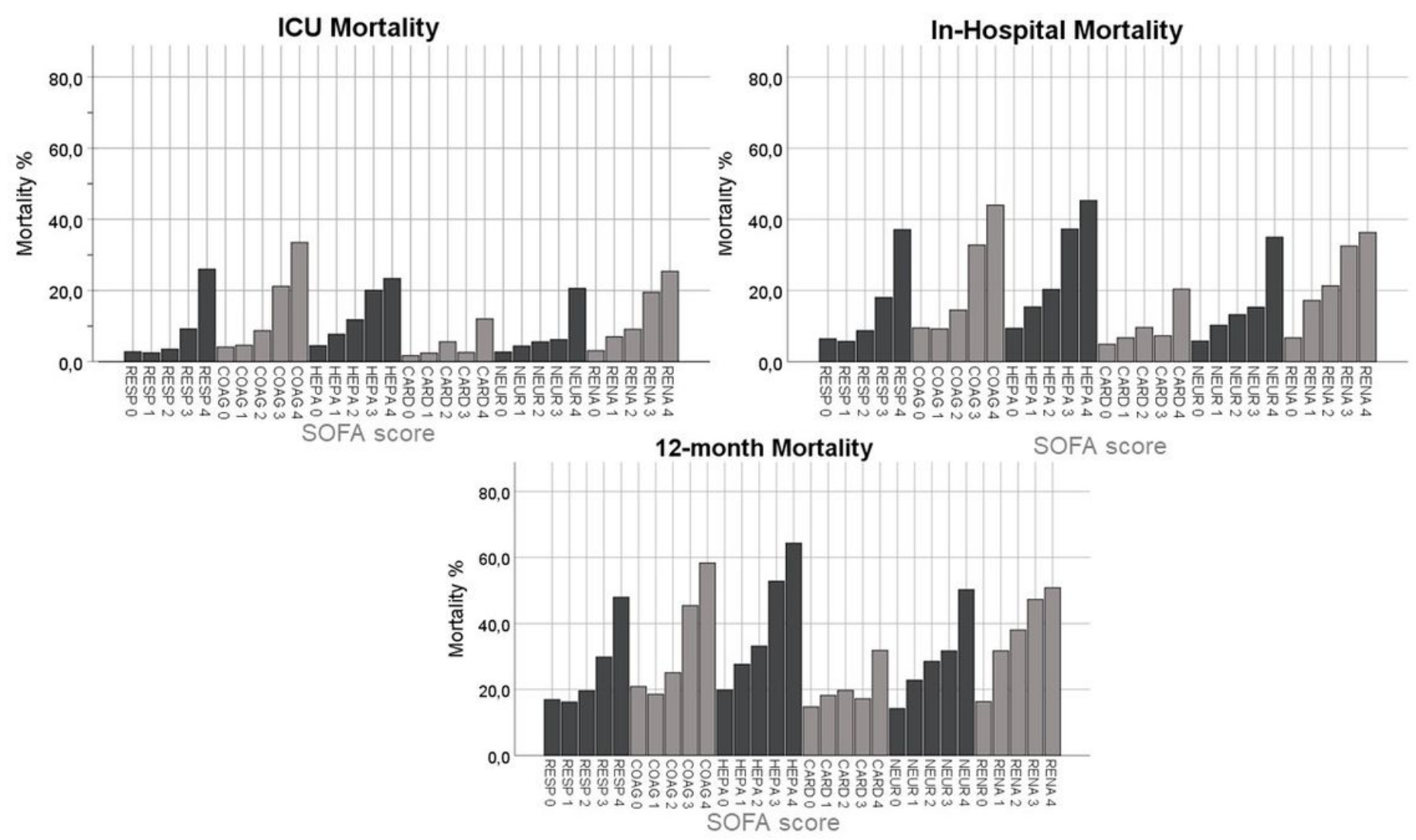

\section{Figure 3}

ICU mortality, in-hospital mortality and 12-month mortality according to SOFA component scores. ICU mortality, in-hospital mortality and 12-month mortality are presented in separate panels. The bars present the mortality in each SOFA score category recorded in the first 24 hours after ICU admission. Mortality increased in a rather linear fashion with increasing SOFA scores in all other components except for the cardiovascular component. In the cardiovascular component, only the most severe category of 4 points was associated with increased mortality. 


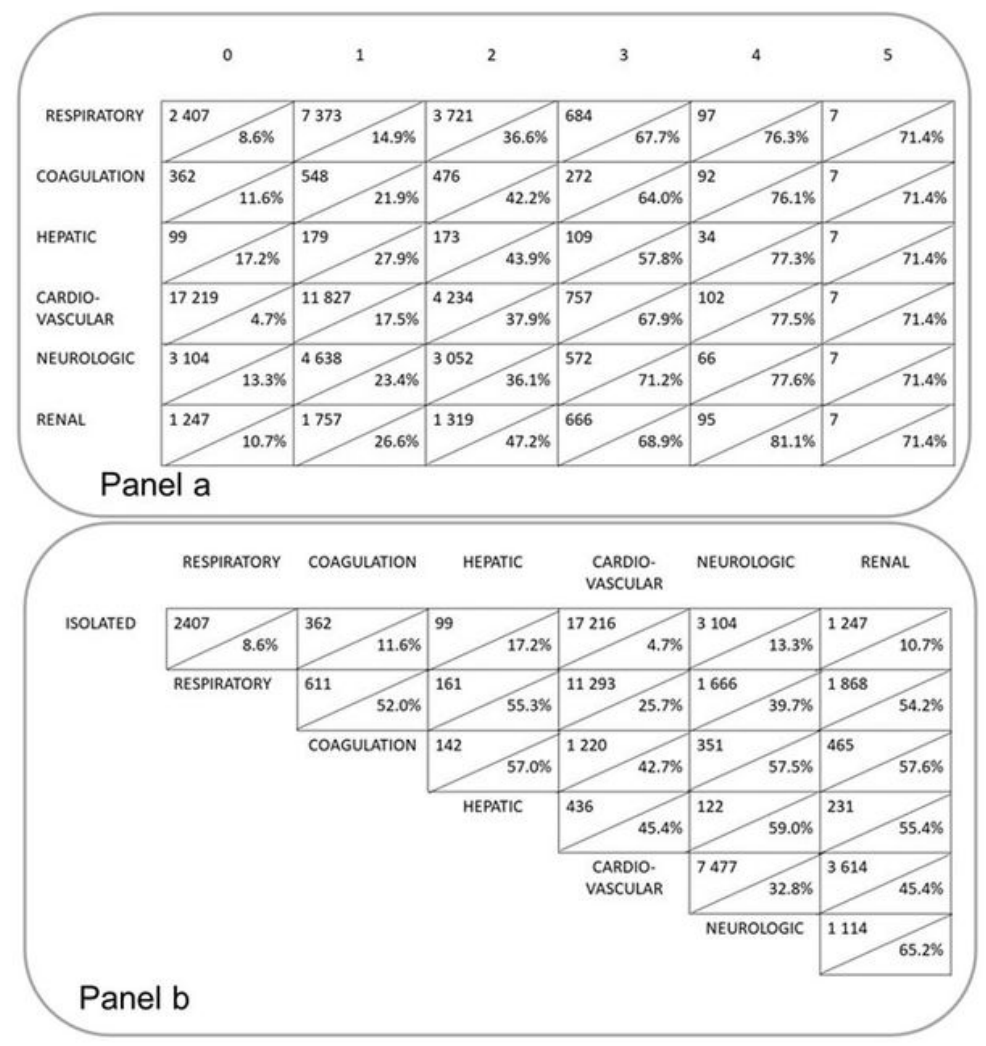

\section{Figure 4}

Mortality according to the number of failing organ systems and mortality in groups with at least two simultaneous organ failures. In panel a, each organ failure is represented by a line. In each box, the number above the diagonal line presents the number of patients with the column title-presented number of additional failing organ systems in addition to the organ failure of that line. The percentage below the diagonal line presents the in-hospital mortality of these patients. Mortality increased with increasing number of failing organ systems. Panel b presents the number of patients with a combination of at least two organ failures. The percentage below the diagonal line shows the in-hospital mortality in patients with that particular combination.

\section{Supplementary Files}

This is a list of supplementary files associated with this preprint. Click to download.

- Additionalfile1.pdf

- GraphicalAbstract.jpg 